\title{
ASSESSMENT
}

\section{A 10-Year Study on the Efficacy of Biomedical Research Support Programs at a Public University}

\author{
Jonathan C. Whittinghill, University of Washington \\ Simeon P. Slovacek, Laura P. Flenoury, Vivian Miu, California State University, Los Angeles
}

\begin{abstract}
The programs Minority Access in Research Careers (MARC) and Research Initiative for Scientific Enhancement (RISE) are funded by the National Institutes of Health to increase the number of students from underrepresented backgrounds earning degrees in the biomedical sciences. This article estimates the impact of participation in MARC and RISE on grade point averages, degree completion, and entrance into biomedical PhD programs. Supported students graduated at higher rates, had higher grade-point averages at graduation, and entered biomedical doctoral programs at much higher rates than students in a propensity score-matched comparison group. Results are comparable with previous study results of similar programs at other institutions and provide further evidence of the valuable support these programs provide to students from underrepresented backgrounds in achieving success in the biomedical sciences.
\end{abstract}

Keywords: biomedical research, efficacy, student support programs, underrepresented students

doi: $10.18833 /$ spur/3/1/3

Despite recent gains, Hispanic, African American, and Native American students participate in science degree programs and careers at rates far below their representation in the US population (National Science Foundation 2007, 2011, 2017). The underrepresentation is particularly acute among doctoral degree recipients; only 11 percent of STEM (science, technology, engineering, and math) doctoral degrees awarded in 2012 were given to students from underrepresented backgrounds, even though these students accounted for 17 percent of STEM bachelor's degrees in the same year (National Center for Education Statistics 2013).

The National Institutes of Health (NIH) have funded a number of programs at the undergraduate and graduate levels to address obstacles faced by underrepresented students in persisting in biomedical science degree programs, including Minority Access in Research Careers (MARC) and the Research Initiative for Scientific Enhancement (RISE). Both programs, currently in place at more than 50 universities in the United States, seek to support undergraduate students in the life sciences through research experiences, mentoring, and academic and financial assistance. The current research examines the outcomes for students at one institution who participated in either or both programs during their academic careers, with particular focus on entrance into science doctoral programs.

\section{Background}

Increasing the number of minority scientists in the United States requires addressing many of the challenges faced by minority college students. Students traditionally underrepresented in the sciences are more likely to have received inadequate preparation in high school (Brown and Campbell 2009), which makes them more likely to drop out prior to earning their undergraduate degrees (Tinto 1982). Underrepresented students are also more likely to cite financial obligations and family pressures as impacting their degree progress (Hurtado et al. 2007). There are also difficulties incorporating students from diverse backgrounds into the academic community and ensuring that all students feel welcomed and encouraged (BonousHammarth 2000, 2005). 
Structured research programs such as MARC and RISE are designed to offer holistic support of underrepresented students during their undergraduate careers (Slovacek et al. 2011). At their core is the placement of underrepresented students in faculty-run research labs, which provide experience working in science that serves not only as a form of instruction but as a way to promote students' perceptions of themselves as scientists (Carpi et al. 2017; Hunter, Laursen, and Seymour 2007; Seymour et al. 2004) and encourage them to pursue careers in the sciences (Kardash 2000; Kinkead 2003; Lopatto 2004). The mentoring relationships that can form between students and the faculty in charge of the labs can also be important for encouraging a sense of belonging in the sciences (Hurtado et al. 2007). Students' academic progress is monitored and supported through advising, tutoring, and supplemental instruction (Peterfreund et al. 2008; Slovacek et al. 2011). This assistance is important for addressing any deficiencies in high school preparation and ensuring that students perform well in gatekeeper courses that are necessary for the degree (Barlow and Villarejo 2004; Pascarella and Terenzini 2005). Equally important is the financial assistance provided to students by MARC and RISE; the stipends paid to supported students relieve them from the burden of large loan debt or part-time work to finance their education.

Previous research into MARC, RISE, and related programs has found positive effects on both graduation and entrance into advanced degree programs (Schultz et al. 2011; Slovacek et al. 2014; Slovacek et al. 2012). The current study extends that research to another institution to examine the impact of participation in MARC and RISE on graduation rates, grade point averages at graduation, and entrance into $\mathrm{PhD}$ programs in the sciences. Comparisons are made between supported students and nonsupported students in the same degree programs, as well as between supported students and a matched comparison group generated by propensity score matching.

\section{Setting}

California State University, Dominguez Hills (CSUDH) is a public university located approximately 20 miles south of Los Angeles, offering bachelor's and master's degrees. As of 2015, it enrolled 12,562 undergraduates and an additional 2,073 graduate students, of which around 70 percent were enrolled full time. CSUDH is a majority Hispanic-serving institution; approximately 60 percent of the student body is of Hispanic origin. African American students make up another 15 percent of the population; white and Asian students compose 10 percent each; and the remaining 5 percent include American Indians, Pacific Islanders, and students who identify as two or more races.

The MARC and RISE programs are aimed at increasing the number of students from backgrounds underrepre- sented in the sciences who enter and succeed in $\mathrm{PhD}$ programs in the sciences, with the goal of improving diversity among research scientists working in the United States. To that end, participants in MARC and RISE are placed in research labs at CSUDH or partnering institutions and paired with a research mentor to help guide them in their development as scientists. Other funded activities include workshops and seminars, networking opportunities, and guidance during the graduate school application process. MARC students receive financial assistance to cover a percentage of their tuition and fees as well as a monthly stipend. RISE students receive a salary to conduct research in the laboratory for a maximum of 15 hours per week during the academic year and 40 hours per week in the summer.

Students who wish to participate in MARC and RISE must commit to majoring in either the natural or social sciences, specifically biology, biochemistry, chemistry, physics, psychology, or sociology. Other criteria for admission include "demonstrated academic ability in coursework," and although there are no specific requirements regarding grades students must maintain a GPA of at least 3.0 once in the program. Prospective students must also submit recommendations from science faculty at CSUDH and a personal statement.

\section{Design}

The initial sample consisted of 15,251 students who were enrolled for at least one semester in a degree program at the College of Natural and Behavioral Sciences (NBS) at California State University, Dominguez Hills between fall 2005 and spring 2017. Of the initial 15,251, approximately 6,000 were excluded because they either entered the university prior to fall 2005 or were still enrolled as undergraduates in 2017. A smaller number of students were excluded for belonging to groups ineligible for MARC or RISE participation, and approximately 700 students were removed due to missing data. A total of 6,163 students were included in the final analysis, of which 60 had been supported by MARC and RISE.

Institutional records furnished information on student demographics; academic background; declared major(s); GPA for each semester of attendance; and, if the student obtained a degree from CSUDH, the field in which it was earned. To this was added data on program participation from the MARC and RISE program office at CSUDH, which also furnished data on participants' entrance into graduate programs in the sciences. Information on the postgraduate plans of both MARC and RISE and nonsupported students was also obtained through the National Student Clearinghouse (2019).

The characteristics of the students in the final sample by MARC and RISE participation are given in Table 1 . 
Students' level at entry is based on the number of course units that students had completed prior to entering the university, either as a student at another institution or through advanced placement exams as a high school student. Students' initial major is defined as the first major they declared; if degrees are offered as both BA and BS, these are treated as separate majors. GPA at entry comes from students' previous institutions, either high school or the transferring institution.

Given the expectations placed upon those in MARC and RISE, participants in the sample were unsurprisingly dissimilar from nonsupported students. On average, students who would later participate in MARC and RISE had higher GPAs at entry to CSUDH than others and were also divided more equally between men and women (overall, 70 percent of students in the full sample were female, and approximately 60 percent were female across the entire university). There were fewer differences in the distribution of racial and ethnic categories, and the two groups were about equal with respect to the percentage of students entering as transfer students and the percentage entering as first-year students. Upon entry to the university, students who would become MARC and RISE participants were more likely to have selected a major that was among those supported by the MARC and RISE program-only 2 percent of students who would later join MARC and RISE declared as their first major one that was unsupported by the program. The MARC and RISE-supported majors were also popular among nonsupported students ( 88 percent selected one of those degree programs upon entry), although the students within that subset of majors showed differences between those who would ultimately join MARC and RISE and

TABLE 1. Comparisons of MARC and RISE Students to Nonsupported Students Prior to Matching

\begin{tabular}{|c|c|c|}
\hline & $\begin{array}{l}\text { MARC and RISE } \\
\qquad(n=60)\end{array}$ & $\begin{array}{l}\text { Non-MARC and RISE } \\
\qquad(n=6,103)\end{array}$ \\
\hline Mean GPA at Entry & 3.24 & 2.86 \\
\hline Female & $50 \%$ & $70 \%$ \\
\hline Mean Age & 22 & 23 \\
\hline \multicolumn{3}{|l|}{ Enrollment status } \\
\hline Transfer & $63 \%$ & $62 \%$ \\
\hline First-time first-year student & $37 \%$ & $38 \%$ \\
\hline \multicolumn{3}{|l|}{ Level at entry } \\
\hline First-year student & $38 \%$ & $35 \%$ \\
\hline Second-year student & $4 \%$ & $15 \%$ \\
\hline Third-year student & $48 \%$ & $38 \%$ \\
\hline Fourth-year student & $9 \%$ & $12 \%$ \\
\hline \multicolumn{3}{|l|}{ Racelethnicity } \\
\hline African American & $28 \%$ & $27 \%$ \\
\hline American Indian & $2 \%$ & $0.3 \%$ \\
\hline Asian & $7 \%$ & $8 \%$ \\
\hline Latinx & $50 \%$ & $55 \%$ \\
\hline Pacific Islander & $2 \%$ & $1 \%$ \\
\hline White & $12 \%$ & $10 \%$ \\
\hline \multicolumn{3}{|l|}{ Initial major } \\
\hline Biology (BA) & $7 \%$ & $7 \%$ \\
\hline Biology (BS) & $20 \%$ & $7 \%$ \\
\hline Biochemistry & $12 \%$ & $2 \%$ \\
\hline Chemistry (BA) & $3 \%$ & $0.3 \%$ \\
\hline Chemistry (BS) & $3 \%$ & $1 \%$ \\
\hline Physics & $3 \%$ & $2 \%$ \\
\hline Psychology & $38 \%$ & $45 \%$ \\
\hline Sociology & $12 \%$ & $23 \%$ \\
\hline Other BS & $2 \%$ & $12 \%$ \\
\hline
\end{tabular}

32 Scholarship and Practice of Undergraduate Research 
those who would not. The difference in declared majors was particularly pronounced in the biological sciences (biology and biochemistry) and the behavioral sciences (sociology and psychology); although psychology was the most common major in both groups (38 percent of MARC and RISE students; 45 percent of non-MARC and RISE students), majors in the biological sciences were more frequently chosen by students who would subsequently be supported by MARC and RISE (39 percent vs. 16 percent).

\section{Propensity Score Matching}

To correct for the lack of balance between MARC and RISE participants and nonsupported students, propensity score matching was used to select a subset of nonsupported students most similar to the MARC and RISE students, conditional on the observed covariates, to serve as a comparison group. First introduced by Rosenbaum and Rubin (1983), propensity score matching (PSM) is a method for estimating the probability of each case being assigned to treatment when that probability cannot be known from the design of the study (i.e., in observational studies). As the assignment mechanism is unknown, PSM estimates the probability of having been selected for the treatment group based on the observed differences between those who were selected and those who were not. More specifically, PSM first models the probability of being in the treatment group (participating in MARC and RISE, in this case), conditional on observed characteristics, then utilizes one of many matching techniques to generate a control group that is comparable, if not equivalent, to the sample of students who received treatment. Treatment effects can then be estimated under the assumption that those effects are no longer confounded by the variables used in matching.

Although estimation of the propensity score is usually performed via logistic regression, this study instead used rareevents logistic regression. Logistic regression is known to consistently underestimate the probability of events that occur only rarely in the data; rare events logistic regression offers a correction to this bias to estimate more realistic probabilities (King and Zeng 2001). To estimate the propensity scores, MARC and RISE participation was regressed on students' GPA at entrance, their initial choice of major, whether they entered as a first-year student or a transfer, and the level at which they entered (first-, second-, third-, or fourth-year), along with the demographic factors of age, gender, and racial/ethnic categories listed in institutional records. The variables used in the model were selected due to their assumed relationship with graduation and were the same as those used in previous PSM models of the impact of structured research programs, by the same authors (Slovacek et al. 2014; Slovacek et al. 2012).

Matches for the 60 MARC and RISE students were selected from the sample of 6,103 nonsupported students using one-to-one nearest neighbor matching without replacement, ensuring that each MARC and RISE student would be matched with at most one non-MARC and RISE student. There are currently no other programs similar to MARC and RISE at CSUDH, so comparison students were considered to have no support beyond what was available to all students enrolled at the university. A caliper of 0.25 standard deviations of the propensity score was used to constrain the maximum difference permitted between matches. Matches using calipers of 0.1 and 0.5 standard deviations were also generated to see how sensitive results were to the characteristics of the matched group; results were largely unaffected by differences in the caliper. Because matches were made without replacement, of the initial 60 students there were 3 for whom no suitable match could be found.

Prior to conducting any matching, the average propensity score among MARC and RISE students was approximately 0.08 , with a standard deviation of 0.1 and a median score close to 0 . Non-MARC and RISE students were less spread out, with a mean of 0.01 and a standard deviation of 0.03 . Figure 1 displays the distribution of scores prior to any matching; although both are right-skewed, nonMARC and RISE students' scores exhibit a much larger peak close to 0 (denoting a very low estimated probability of participation), whereas the distribution of scores among MARC and RISE students show a longer tail. Post-matching, the distribution of propensity scores were essentially identical between the two groups (see Figure 2).

\section{Results}

The data permit two sets of comparisons: all MARC and RISE-supported students with all non-MARC and RISE students, and the matched MARC and RISE students to the matched comparison group. In both cases those students who participated in MARC and RISE compared favorably to other students; nearly all (97 percent) of the 60 MARC and RISE students who were no longer enrolled in the data set earned a degree in the sciences from CSUDH. Among all non-MARC and RISE students in the College of Natural and Behavioral Sciences who were no longer enrolled, 49 percent earned a degree in the sciences. If the sample of non-MARC and RISE students was limited to just those who majored in MARC and RISE-supported degree programs, that number rose to 52 percent having graduated (see Table 2 ). Moving to the matched groups, 96 percent of the matched MARC and RISE students graduated, compared to 61 percent of the students from the comparison group. MARC and RISE-supported students also exhibited higher grade point averages at graduation than those who were unsupported. The mean GPA at graduation for MARC and RISE students was 3.48, compared to 3.28 for the matched comparison group and 3.14 among all nonsupported students (see Table 2). 
FIGURE 1. Distribution of Propensity Scores, Pre-Matching

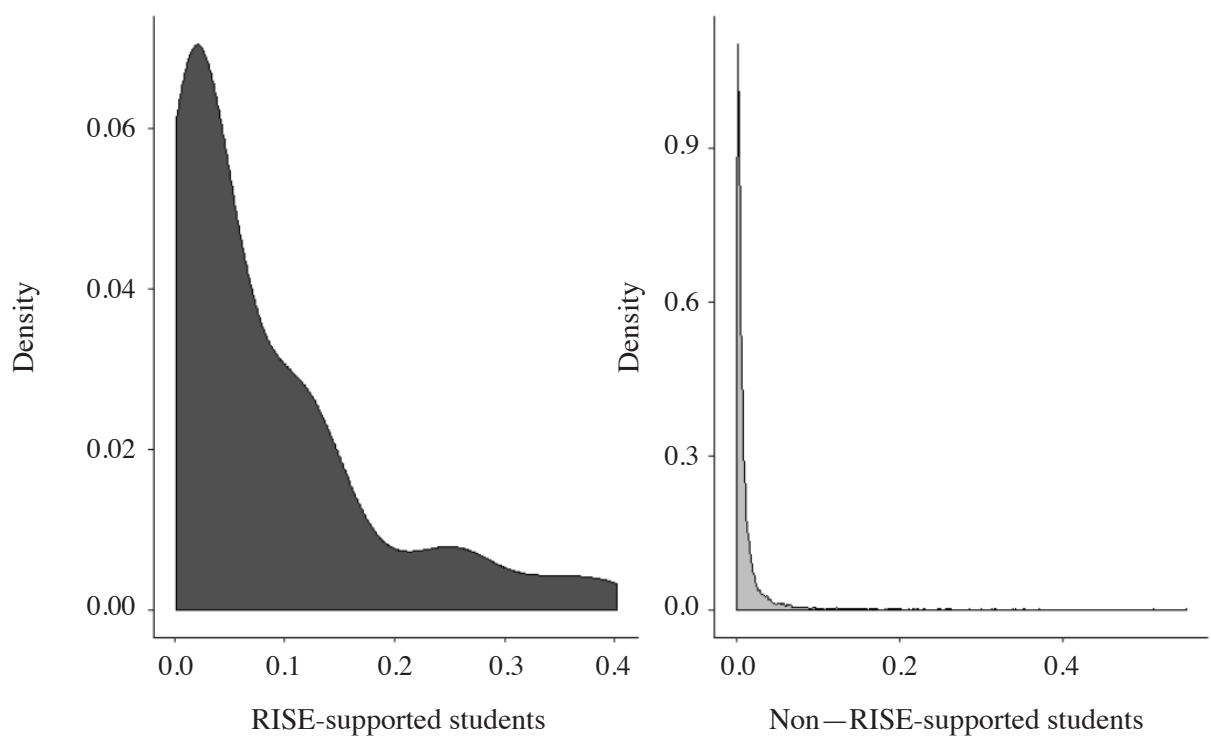

FIGURE 2. Distribution of Propensity Scores, Post-Matching
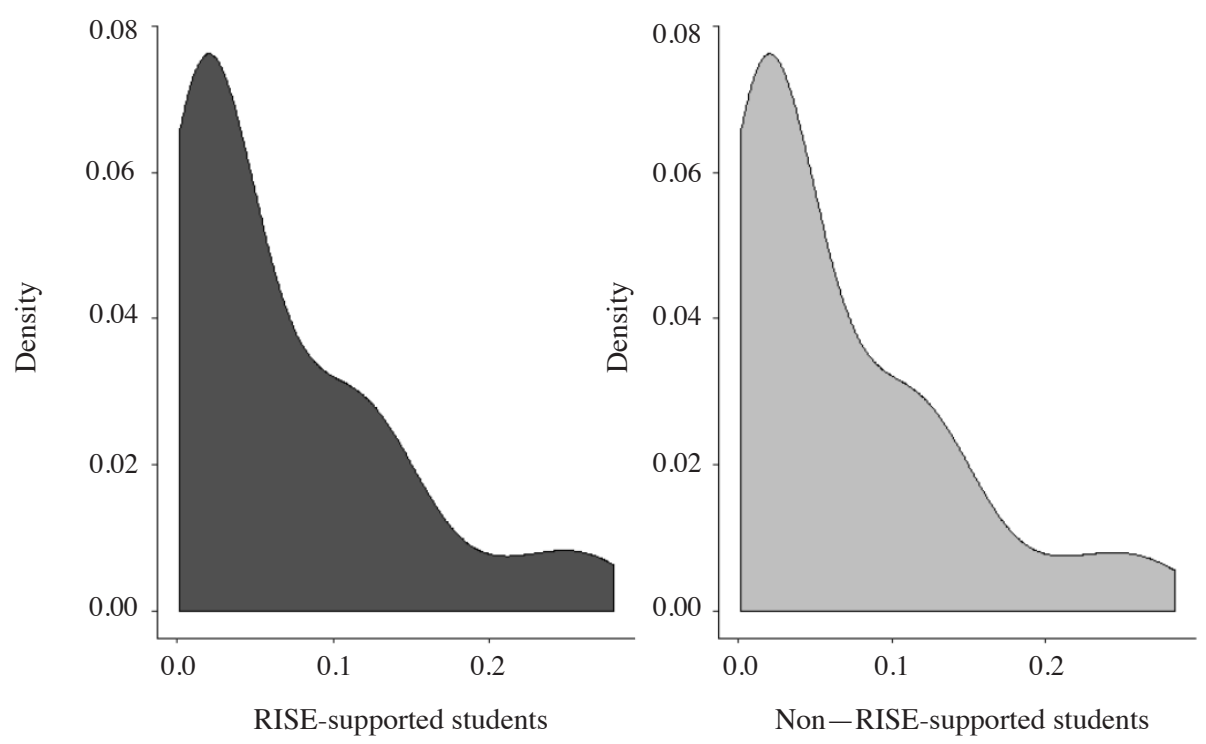

TABLE 2. Outcomes: Mean GPA at Graduation, Graduation Rates, and Entrance into Science PhD Programs

\begin{tabular}{|c|c|c|c|c|}
\hline & $N$ & $\begin{array}{l}\text { Mean GPA } \\
\text { at graduation }\end{array}$ & Graduated & $\begin{array}{c}\text { Entered science } \\
\text { PhD programs }\end{array}$ \\
\hline \multicolumn{5}{|l|}{ Pre-matching } \\
\hline All MARC and RISE students & 60 & 3.50 & $97 \%$ & \\
\hline All nonsupported students & 6,103 & 3.14 & $52 \%$ & - \\
\hline \multicolumn{5}{|l|}{ Post-matching } \\
\hline MARC and RISE students & 57 & 3.48 & $96 \%$ & $62 \%$ \\
\hline Matched comparison students & 57 & 3.28 & $61 \%$ & $9 \%$ \\
\hline
\end{tabular}


TABLE 3. Average Treatment Effect Estimates: Graduation and Entrance into Science PhD Programs

\begin{tabular}{|l|c|c|c|c|}
\hline & $\begin{array}{c}N \\
\text { (MARC and RISE) }\end{array}$ & $\begin{array}{c}\text { N } \\
\text { (Nonsupported) }\end{array}$ & $\begin{array}{c}\text { Treatment } \\
\text { effect }\end{array}$ & Std. err \\
\hline $\begin{array}{l}\text { Graduation with STEM degree } \\
\text { Regression-adjusted }\end{array}$ & 60 & 6,103 & 0.45 & 0.02 \\
$\begin{array}{l}\text { MARC and RISE participation } \\
\text { only } \\
\text { MARC and RISE participation } \\
+ \text { controls }\end{array}$ & 60 & 6,103 & 0.68 & 0.14 \\
$\begin{array}{l}\text { Propensity score-matched } \\
\text { Entrance into science PhD }\end{array}$ & 57 & 57 & 0.35 & 0.07 \\
\hline \begin{tabular}{l} 
Propensity score-matched \\
\hline
\end{tabular}
\end{tabular}

The largest differences between MARC and RISE students and nonsupported students related to the pursuit of doctoral degrees in the sciences. Among the matched MARC and RISE students who earned a degree from CSUDH, 62 percent gained acceptance into a science doctoral program, whereas only 11 percent of degree earners in the matched comparison group did so (data on the pursuit of science $\mathrm{PhDs}$ were only collected for the matched comparison group). At the time data were collected, not every graduate had had sufficient time to apply and enter a doctoral program; however students supported by MARC and RISE overall had graduated more recently than those in the comparison group (median graduation year was 2013 for MARC and RISE students and 2011 for comparison group students), so the differences in pursuit of doctoral degrees were not due to comparison students having had less time to enter PhD programs. Table 2 summarizes the comparisons between MARC and RISE, non-MARC and RISE, and matched students.

Average treatment effects for participation in MARC and RISE programs were defined as the estimated difference in the proportion of graduates between participants and nonparticipants, and the estimated difference in the proportion entering science doctoral programs between participants and nonparticipants. To the extent that the matched group offers a valid comparison to the MARC and RISE students, the treatment effects can be interpreted as the impact of the program on student participants with respect to graduation and entrance into science $\mathrm{PhD}$ programs.

Among the matched groups, logistic regression was used to model the probability of each outcome; treatment effects were calculated as the difference between the estimated probabilities of graduation and entrance into science $\mathrm{PhD}$ programs for MARC and RISE students and those probabilities for nonsupported students. The match package in $\mathrm{R}$ (Sekhon 2011) was used for that calculation and to adjust for standard errors based on the matching having been conditional on the estimated, rather than true, propensity score (Abadie and Imbens 2006). The treatment effect of MARC and RISE participation on graduation from CSUDH was also estimated using logistic regression on the full sample, using as controls the same variables that were used for matching. This treatment effect was the estimate obtained by ignoring the lack of covariate balance and including the matching variables as controls in the regression model. Differences between this estimate and those obtained using propensity score matching were an informal indicator of the bias introduced by not first adjusting for differences between MARC and RISE students and nonsupported students.

The treatment effect related to graduation from CSUDH with a degree in a STEM field within each matched group was 0.35 (see Table 3). That is, the percentage of MARC and RISE students graduating was estimated to be 35 percentage points greater than it would have been had those students lacked the support and training that MARC and RISE provided. The nonmatched estimates of this effect were 0.45 , regressing graduation on only MARC and RISE participation, and 0.68 if one added the matching variables as controls. The magnitude of difference between this effect and the effects from the matched groups suggested that ignoring covariate imbalance between MARC and RISE students and non-MARC and RISE students would greatly overestimate the impact of program participation on graduation.

Turning to entrance to $\mathrm{PhD}$ programs in the sciences, it was not possible to obtain data on the postgraduation academic careers of all students, so the sole treatment effect estimated was for the difference in science $\mathrm{PhD}$ entrance rates between MARC and RISE students and matched students. The effect of the MARC and RISE program on participating students' entrance into science $\mathrm{PhD}$ programs 
was estimated to be 0.53 , meaning there was a 53 percentage point increase in the proportion of students gaining entrance to $\mathrm{PhD}$ programs from what would be expected had those students not participated in MARC and RISE (see Table 3). That is, it was estimated that without the support of the programs approximately 9 percent of students would have been expected to enter $\mathrm{PhD}$ programs in the sciences. Instead 62 percent of students entered science $\mathrm{PhD}$ programs, a difference of 53 percentage points.

\section{Discussion}

Students who were supported by the MARC and RISE programs graduated at higher rates than the matched comparison group and had earned higher GPAs at the time they graduated. Differences in GPA were not large, only 0.2 on a 4-point scale, however even that small of a difference can be consequential for graduate school admissions. Most importantly, MARC and RISE students entered science doctoral programs at far higher rates than those students who lacked the support the programs provide. The results are in line with previous studies of MARC and RISE programs at other public institutions. Slovacek and colleagues (2012) also compared MARC and RISE students to a propensity score-matched comparison group at the California State University, Los Angeles and found similar estimates of program participation: mean GPA at graduation for supported and matched students differed by approximately 0.2 , and 48 percent of supported students entered science doctoral programs, compared to approximately 5 percent of matched students. Previous research into programs similar to MARC and RISE has also found comparable impacts from participation; an analysis of the Meyerhoff Scholars Program at the University of Maryland, Baltimore County (Maton, Hrabowski, and Schmitt 2000) found that program participants had higher GPAs in STEM courses and graduated in STEM majors at nearly twice the rate of students who declined an offer to participate in the program. The same comparison found that approximately 46 percent of Meyerhoff participants pursued graduate study in the sciences, in contrast to only 9 percent of those who declined participation. Another study of a structured research program focused on biology students (Barlow and Villarejo 2004) did not find large differences between supported students and those who declined participation in most outcomes, although students who participated in the program did enter $\mathrm{PhD}$ programs at higher rates than university graduates as a whole.

Although the quantitative data present strong evidence for the efficacy of the programs in achieving their stated goals, it explains less about the exact mechanisms that lead to MARC and RISE students outperforming their peers. Annual focus groups conducted during a five-year period with 70 RISE and MARC students revealed that the activities most closely aligned with the work they would perform during graduate studies were perceived as the most helpful. Working in research labs, attending academic conferences, and participating in workshops and seminars were all cited as positive influences on remaining in school and pursuing graduate education. This is consistent with the idea that providing research experiences not only trains students as scientists but accustoms them to scientific culture (Hunter, Laursen, and Seymour 2007; Seymour et al. 2004). Encouraging students to see themselves as scientists can impact their decision to further their education and pursue science-related careers (Lopatto 2004). Financial support was also important, giving students protected time to focus on their studies rather than working to support themselves, which has been found to have a negative impact on persistence (Astin 1982; Gardner and Broadus 1990). Hurtado and colleagues (2007) found that students from underrepresented groups were frequently impacted by financial and family pressures and more concerned with the ability to finance college.

The qualitative data may prove more useful for determining how best to scale-up programs like MARC and RISE; although the programs deserve praise for promoting science careers to students traditionally underrepresented in science fields, correcting that underrepresentation will require a greater commitment than 20 to 30 students per year per institution. MARC and RISE make considerable investments in participating students, and large-scale interventions will likely be unable to provide all the various supports they comprise. The importance students gave to research experiences suggests that institutions of higher education should strive to create opportunities for students to receive hands-on training in their chosen fields and as well encourage them to view themselves as practicing scientists, either through interventions like MARC and RISE or through changes to pedagogy and coursework. Equally important is the need to foster inclusive environments in all departments that help students from all backgrounds participate in the community. Given how important financial support can be to low-income students, the cost of attendance should be kept as low as possible. The need for increasing support of underrepresented students in the sciences remains undisputable. Although federally funded programs aimed at increasing the number of underrepresented minorities in the sciences have existed for over four decades, from 2006 to 2016 the percentage of science and engineering doctorates awarded to students from underrepresented backgrounds has only increased 3 percent (from 11 percent to 14 percent; National Science Foundation 2019), even as underrepresented groups continued to become a larger share of the population attending US higher education institutions.

A perennial issue with research into structured research programs is their relatively small sample sizes and an application process that selects students based in part on their intention to pursue advanced degrees. Although 
techniques such as propensity score matching can reduce or eliminate observable differences between supported and nonsupported students, there remains the potential for bias due to unobservable traits, such as motivation and initial career goals. There is also a need for further work to examine the long-term impact of these programs on supported students' career paths. It is still not known how many ultimately complete their doctoral programs and become practicing senior scientists in academia, government, and private industry. Another issue that bears study is the role that nonacademic factors play in student persistence. The intention to pursue doctoral study in the sciences was not measured in this study and may certainly account for some of the outcome differences between MARC and RISE students and those in the matched comparison group. That said, Schultz and colleagues (2011), in an examination of RISE students at 25 universities, found that although RISE students and those in a propensity score-matched group had initially roughly equal interest in pursuing advanced degrees students in RISE were able to sustain that interest through subsequent years of schooling while comparison students saw a gradual decline. Thus, interest in doctoral study may be less a confounding variable and more another mechanism by which programs like MARC and RISE promote future scientists. Lopatto (2017) argues that research into undergraduate research programs should do more to incorporate information on factors external to the university that influence student success. Although institutions have little control over those factors, they nonetheless form the context within which programs like MARC and RISE operate. Thus, any analysis of the success of these programs should ideally be understood within that context.

\section{Acknowledgments}

The authors would like to thank the Office of Institutional Research, Assessment, and Planning at California State University, Dominguez Hills as well as the MARC and RISE program office for providing the data. This project is supported by RISE grant number 5R25GM062252-15 and MARC grant number 5T34GM008683-18.

\section{References}

Abadie, Alberto, and Guido W. Imbens. 2006. "Large Sample Properties of Matching Estimators for Average Treatment Effects." Econometrica 74: 235-267. doi: 10.1111/j.14680262.2006.00655.x Accessed September 12, 2019. https://economics.mit.edu/files/11867

Astin, Alexander W. 1982. Minorities in American Higher Education: Recent Trends, Current Prospects and Recommendations. San Francisco: Jossey-Bass.

Barlow, Amy E. L., and Merna Villarejo. 2004. "Making a Difference for Minorities: Evaluation of an Educational Enrichment Program." Journal of Research in Science Teaching 41: 861-881. doi: 10.1002/tea.20029. Accessed September 12, 2019. https:// escholarship.org/content/qt6ht0s15h/qt6ht0s15h.pdf?t=lnp96p
Bonous-Hammarth, Marguerite. 2000. "Pathways to Success: Affirming Opportunities for Science, Math, and Engineering Majors." Journal of Negro Education 69: 92-111.

Bonous-Hammarth, Marguerite. 2005. "Promoting Student Participation in Science, Technology, Engineering and Mathematics Careers." In Higher Education in a Global Society: Achieving Diversity, Equity and Excellence, ed. Walter R. Allen, Marguerite Bonous-Hammarth, and Robert T. Teranishi, 269-282. Advances in Education in Diverse Communities: Research Policy and Praxis, vol. 5. Bingley, UK: Emerald Group. doi: 10.1016/s1479$358 \mathrm{x}(05) 05013-8$

Brown, Richard, and D. Michael Campbell. 2009. "Recent Trends in Preparing Ethnic Minorities for Careers in Math and Science." Journal of Hispanic Higher Education 8: 225-241. doi: $10.1177 / 1538192708326392$

Carpi, Anthony, Darcy M. Ronan, Heather M. Falconer, and Nathan H. Lents. 2017. "Cultivating Minority Scientists: Undergraduate Research Increases Self-Efficacy and Career Ambitions for Underrepresented Students in STEM." Journal of Research in Science Teaching 54: 169-194. doi: 10.1002/tea.21341

Gardner, Philip D., and Angela Broadus. 1990. Pursuing an Engineering Degree: An Examination of Issues Pertaining to Persistence in Engineering. East Lansing, MI: Collegiate Employment Research Institute, Michigan State University.

Hunter, Anne-Barrie, Sandra L. Laursen, and Elaine Seymour. 2007. "Becoming a Scientist: The Role of Undergraduate Research in Students' Cognitive, Personal, and Professional Development." Science Education 91: 36-74. doi: 10.1002/ sce. 20173

Hurtado, Sylvia, June C. Han, Victor B. Sáenz, Lorelle L. Espinosa, Nolan L. Cabrera, and Oscar S. Cerna. 2007. "Predicting Transition and Adjustment to College: Biomedical and Behavioral Science Aspirants' and Minority Students' First Year of College." Research in Higher Education 48: 841-887. doi: 10.1007/ s11162-007-9051-x

Kardash, CarolAnne M. 2000. "Evaluation of Undergraduate Research Experience: Perceptions of Undergraduate Interns and Their Faculty Mentors." Journal of Educational Psychology 92: 191-201. doi: 10.1037/0022-0663.92.1.191

King, Gary, and Langche Zeng. 2001. "Logistic Regression in Rare Events Data." Political Analysis 9: 137-163. doi: 10.1093/ oxfordjournals.pan.a004868

Kinkead, Joyce. 2003. "Learning through Inquiry: An Overview of Undergraduate Research." New Directions for Teaching and Learning 93: 5-18. doi: 10.1002/t1.85

Lopatto, David. 2004. "Survey of Undergraduate Research Experiences (SURE): First Findings." Cell Biology Education 3: 270-277. doi: 10.1187/cbe.04-07-0045

Lopatto, David. 2017. "Adapting to Change: Studying Undergraduate Research in the Current Education Environment." Scholarship and Practice of Undergraduate Research 1(1): 5-10. doi: 10.18833/spur/1/1/7

Maton, Kenneth I., Freeman A. Hrabowski III, and Carol L. Schmitt. 2000. "African American College Students Excelling in the Sciences: College and Postcollege Outcomes in the Meyerhoff 
Scholars Program." Journal of Research in Science Teaching 37: 629-654. doi: 10.1002/1098-2736(200009)37:7<629::aidtea2>3.0.co; $2-8$

National Center for Education Statistics (NCES). 2013. Integrated Postsecondary Education Data System (IPEDS). Washington, DC: Author. https://nces.ed.gov/ipeds

National Science Foundation (NSF). 2007. Women, Minorities, and Persons with Disabilities in Science and Engineering: 2007. NSF 07-315. Alexandria, VA: Author. Accessed September 12, 2019. https://ncses.nsf.gov/pubs/nsf19304/prior-releases

National Science Foundation (NSF). 2011. Women, Minorities, and Persons with Disabilities in Science and Engineering: 2011. NSF 11-309. Alexandria, VA: Author. Accessed September 12 , 2019. https://ncses.nsf.gov/pubs/nsf19304/prior-releases

National Science Foundation (NSF). 2017. Women, Minorities, and Persons with Disabilities in Science and Engineering: 2017. NSF 17-310. Alexandria, VA: Author. Accessed September 12, 2019. https://www.nsf.gov/statistics/2017/nsf17310/digest/ about-this-report

National Science Foundation (NSF). 2019. Women, Minorities, and Persons with Disabilities in Science and Engineering: 2019. NSF 19-304. Alexandria, VA: Author. Accessed September 12 , 2019. https://ncses.nsf.gov/pubs/nsf19304

National Student Clearinghouse. 2019. Postsecondary Data Partnership. https://studentclearinghouse.info/onestop/wp-content/ uploads/Postsecondary-Data-Partnership-factsheet.pdf

Pascarella, Ernest T., and Patrick T. Terenzini. 2005. A Third Decade of Research. Vol. 2 of How College Affects Students. San Francisco: Jossey-Bass.

Peterfreund, Alan R., Kenneth A. Rath, Samuel P. Xenos, and Frank Bayliss. 2008. "The Impact of Supplemental Instruction on Students in STEM Courses: Results from San Francisco State University." Journal of College Student Retention: Research, Theory \& Practice 9: 487-503. doi: 10.2190/cs.9.4.e

Rosenbaum, Paul R., and Donald B. Rubin. 1983. "The Central Role of the Propensity Score in Observational Studies for Causal Effects." Biometrika 70: 41-55. doi: 10.1093/biomet/70.1.41

Schultz, P. Wesley, Paul R. Hernandez, Anna Woodcock, Mica Estrada, Randie C. Chance, Maria Aguilar, and Richard T. Serpe. 2011. "Patching the Pipeline: Reducing Educational Disparities in the Sciences through Minority Training Programs." Educational Evaluation and Policy Analysis 33: 95-114. doi: $10.3102 / 0162373710392371$

Sekhon, Jasjeet S. 2011. "Multivariate and Propensity Score Matching Software with Automated Balance Optimization: The Matching Package for R." Journal of Statistical Software 42(7): 1-52. doi: $10.18637 /$ jss.v042.i07

Seymour, Elaine, Anne-Barrie Hunter, Sandra L. Laursen, and Tracee DeAntoni. 2004. "Establishing the Benefits of Research Experiences for Undergraduates in the Sciences: First Findings from a Three-Year Study." Science Education 88: 493-534. doi: $10.1002 /$ sce. 10131
Slovacek, Simeon, Jonathan Whittinghill, Laura Flenoury, and Yee-Lam Lee. 2014. "The Impact of Graduate-Level Structured Research Programs on Degree Attainment and Doctoral Study." Journal of Education and Human Development 3(1): 27-54. Accessed September 12, 2019. http://jehdnet.com/journals/jehd/ Vol_3_No_1_March_2014/3.pdf

Slovacek, Simeon, Jonathan Whittinghill, Laura Flenoury, and David Wiseman. 2012. "Promoting Minority Success in the Sciences: The Minority Opportunities in Research Programs at CSULA." Journal of Research in Science Teaching 49: 199-217. doi: 10.1002/tea.20451

Slovacek, Simeon P., Jonathan C. Whittinghill, Susan Tucker, Kenneth A. Rath, Alan R. Peterfreund, Glenn D. Kuehn, and Yvonne G. Reinke. 2011. "Minority Students Severely Underrepresented in Science, Technology, Engineering and Math." Journal of STEM Education 12(1): 5-16.

Tinto, Vincent. 1982. "Limits of Theory and Practice in Student Attrition." Journal of Higher Education 53: 687-700. doi: 10.2307/1981525

\section{Jonathan C. Whittinghill}

University of Washington, jwhitt@uw.edu

Jonathan C. Whittinghill is a research consultant in the Foster School of Business at University of Washington.

Simeon P. Slovacek is an emeritus professor of education at California State University, Los Angeles (Cal State LA) and program director of the Program Evaluation \& Research Collaborative (PERC). Under his 30-year leadership of PERC, he has worked on dozens of evaluation grants and contracts for programs funded by NIH, NSF, NASA, the US Department of Education, First 5 LA, the Los Angeles Annenberg Metropolitan Project (LAAMP), and AmeriCorps. Slovacek has authored and coauthored 120 evaluation reports on his evaluation work. Furthermore, he has authored more than a dozen research articles ranging in topics from computer education and the impact of STEM student support programs on graduation rates and $P h D$ placement to cancer incidence in Trinidad and Tobago.

Laura P. Flenoury graduated from Cal State LA with a bachelor of arts in psychology. She works at PERC at Cal State LA as the administrative analyst/specialist. During her 16-year tenure at PERC, she has managed multiple evaluation projects funded by NIH, NSF, the US Department of Education, and First 5 LA. She has coauthored more than 50 evaluation reports on this work and also has contributed to several research articles on STEM student support programs.

Vivian Miu graduated from McGill University with a bachelor of science in psychology and from Cal State LA with a master of arts in special education. She currently works as an evaluation associate at PERC at Cal State LA and has contributed to evaluation reports for programs funded by NASA, the US Department of Education, and NIH. 